Sharif University of Technology
Scientia Iranica
SCIENTIA
I RAN ICA

\title{
Non-oxidative methane aromatization by bimetallic (La, Co, Pd, and Pt) M-Zn/HZSM-5: Impact of propane addition
}

\author{
P. Moghimpour Bijani ${ }^{a}, b, *$, M. Sohrabi ${ }^{a}$, S. Sahebdelfar ${ }^{b}$, and \\ A. Gholidoust ${ }^{c}$ \\ a. Department of Chemical Engineering, Amirkabir University of Technology, Hafez Avenue, Tehran, P. O. Box 15875-4413, Iran. \\ b. Catalyst Research Group, Petrochemical Research and Technology Company, National Petrochemical Company, Tehran, P.O. \\ Box 1435884711, Iran. \\ c. Department of Civil and Environmental Engineering, University of Alberta, Edmonton, AB T6G, 2 W2, Canada.
}

Received 27 September 2017; received in revised form 5 November 2017; accepted 27 January 2018

\author{
KEYWORDS \\ Methane; \\ Propane; \\ Aromatization; \\ Zn-modified HZSM-5; \\ Promoter.
}

\begin{abstract}
The non-oxidative aromatization of methane was studied over M-Zn/HZSM$5(\mathrm{M}=\mathrm{La}, \mathrm{Co}, \mathrm{Pd}$, and $\mathrm{Pt})$ catalysts using propane as a co-reactant. The catalysts were characterized by BET, SEM, NH3-TPD, and XRD techniques. Catalytic tests were performed in a fixed-bed reactor at $823 \mathrm{~K}$ using a mixture of methane, propane, and nitrogen with ratio of $6 / 1 / 1.3$, respectively. Propane conversion was above $50 \%$ and remained stable in the first 12 hours on stream; however, the methane conversion rapidly dropped from a high of about $10 \%$ to zero within 4 hours, implying the absence of a stoichiometric reaction between the reactants. Both zinc and the second metal (M) had a beneficial effect on aromatic selectivity, and Pt-Zn/HZSM-5 exhibited the highest aromatic yields and catalyst stability. The results of the present study showed that co-feeding of methane with propane cannot successfully induce methane to participate in aromatization reactions.
\end{abstract}

(C) 2018 Sharif University of Technology. All rights reserved.

\section{Introduction}

Transformation of lower alkanes into more valuable commodity chemicals is still an issue in both applied and fundamental researches [1,2]. High thermodynamic stability and low reactivity of methane impose an obstacle on methane's selective transformation into valuable chemicals [3].

The dehydroaromatization of methane to aromat-

\footnotetext{
*. Corresponding author. Tel.: +982144787100;

Fax: +982144787505

E-mail address: p.bijani@aut.ac.ir (P. Moghimpour Bijani)
}

doi: $10.24200 /$ sci. 2018.5050 .1062 ics is an equilibrium-limited reaction requiring high temperatures (i.e., above $1000 \mathrm{~K}$ ) to gain acceptable yields. However, such severe reaction conditions could lead to methane pyrolysis and coke formation [4]. Consequently, despite significant efforts made during the past two decades, the issue of the selective transformation of methane to aromatics is still a challenge in the field of catalysis [5].

Co-feeding methane with other hydrocarbons resulted in higher yields of methane conversion than thermodynamic equilibrium conversion $[5,6]$. For example, adding only a small percent of ethane caused a remarkable increase in benzene formation over the Mo/HZSM- 5 catalyst at $998 \mathrm{~K}$. (The formation rate of benzene was enhanced by a factor of 1.68 for an 
ethane content of $6.3 \%$.) Moreover, directly adding methane into a mixture of $\mathrm{C}_{3}-\mathrm{C}_{4}$ alkanes at a relatively mild temperature of $823 \mathrm{~K}$ yielded a high methane conversion (ca. 15\%) over Zn- or Ga-promoted zeolite catalysts $[7,8]$. Recently, it has been found that ${ }^{13} \mathrm{CH}_{4}$ can be converted into aromatics in the presence of $\mathrm{C}_{3} \mathrm{H}_{8}$ at moderate temperatures (ca. $823 \mathrm{~K}$ ) over an HZSM-5 catalyst impregnated with $\mathrm{Ga}, \mathrm{Re}, \mathrm{Zn}, \mathrm{Cu}-\mathrm{Zn}, \mathrm{Mo}-\mathrm{Zn}$, Pt-Zn, and La-Zn [9].

Zinc- or gallium-impregnated ZSM-5 zeolites are potential catalysts for the conversion of light alkanes to aromatics. Gallium has less volatility at low pressures and high temperatures and shows moderate to low hydrogenolysis activity. However, toxicity and high price of gallium salts limit gallium's applications. The $\mathrm{Zn}$ ion in the di-cation state $\left(\mathrm{Zn}^{2+}\right)$ exhibits good dehydrogenation activity and aromatization selectivity. $\mathrm{Zn}^{2+}$ appears to be stable in cation-exchanged positions and remains unreduced under alkane conversion conditions. Using a Zn-based HZSM-5 catalyst, instead of Ga-based HZSM-5, might be preferential from environmental and economic standpoints [10]. Therefore, further studies on such a catalyst could be of interest.

According to previous studies, several metals were employed to improve the catalytic activity of Zn/HZSM-5 catalyst for the co-aromatization of $\mathrm{CH}_{4}$ and propane. Adding a secondary metal modified the activity, selectivity, and stability of the catalysts in light alkane aromatization.

However, some researchers have reported contradictory results. Naccache et al. [11], for instance, observed that $\mathrm{H}$-galloaluminosilicate could not activate $\mathrm{CH}_{4}$ and that ${ }^{13} \mathrm{CH}_{4}$ may not be utilized in aromatization reactions involving $\mathrm{C}_{2} \mathrm{H}_{4} / \mathrm{CH}_{4}$ or $\mathrm{C}_{3} \mathrm{H}_{6} / \mathrm{CH}_{4}$ mixtures at low temperatures (563-773 K). Brandford et al. [12] reported that methane conversion was even suppressed in the presence of ethane at $973 \mathrm{~K}$.

Methane can be produced not only as a byproduct in propane aromatization, but also from undesired side reactions during propane cracking and hydrogenolysis. This complicates the analysis of reaction data and reduces the net methane conversion.

The mechanism of methane/propane coaromatization is still controversial. Since no methane conversion on un-promoted zeolites and in the absence of higher hydrocarbons has been observed, the formation of carbenium ion intermediates from the heavier hydrocarbons was proposed. The carbenium ion reacts with the pre-activated methane on metal oxide, yielding $\mathrm{CH}_{2}$ species by hydride transfer. Subsequent dimerization of $\mathrm{CH}_{2}$ species results in ethylene which, upon oligomerization and dehydrocyclization, converts into aromatics [6]. More recently, Luzgin et al. [13] used ${ }^{13} \mathrm{C}$ labeled methane, and found that methane was not involved in the aromatization reaction; however, it was involved in methylation of aromatics formed exclusively from propane in a temperature range of $823-873 \mathrm{~K}$. Subsequent intramolecular rearrangements resulted in the involvement of methane carbon in the aromatic ring. The role of $\mathrm{ZnO}$ is to provide methoxy groups.

The given conflicting literature concerning the role of higher hydrocarbons in methane-to-aromatics conversion $[5,6,11,12]$ led to the present work that investigated the co-aromatization of a mixture of methane and propane on different catalysts under conventional reaction conditions. The catalysts were prepared by impregnating the parent Zn/HZSM-5 catalyst with a second promoter ( $\mathrm{La}, \mathrm{Pt}, \mathrm{Co}$, and $\mathrm{Pd}$ ) and performing co-aromatization reactions. The present study appears to be the first attempt to apply such catalysts in co-aromatization under the same reaction conditions.

\section{Experimental}

\subsection{Catalyst preparation}

First, the Na form of ZSM-5 zeolite with $\mathrm{SiO}_{2} / \mathrm{Al}_{2} \mathrm{O}_{3}$ ratio of 40 (provided by Zeochem Company) was converted into ammonium form $\left(\mathrm{NH}_{4} \mathrm{ZSM}-5\right)$ by ion exchange which was repeated four times, each lasted about $4 \mathrm{~h}$, using $1 \mathrm{~N} \mathrm{NH}_{4} \mathrm{NO}_{3}$ aqueous solution at $358 \mathrm{~K}$. The exchange media were filtered, washed, and dried at $383 \mathrm{~K}$ overnight. HZSM-5 catalysts were prepared by calcination of $\mathrm{NH}_{4} \mathrm{ZSM}-5$ sample at 773 $\mathrm{K}$ for $10 \mathrm{~h}$.

The resulting HZSM-5 zeolite was converted into a Zn/HZSM-5 form by wet impregnation for low Zn loadings $(0.25,0.40$, and $0.60 \mathrm{wt} \%)$ and dry impregnation for moderate Zn loadings (1.0, 2.0, and $4.0 \mathrm{wt} \%$ ) with an appropriate amount of a zinc nitrate hexahydrate $\left(\mathrm{Zn}\left(\mathrm{NO}_{3}\right)_{2} \cdot 6 \mathrm{H}_{2} \mathrm{O}\right.$, Merck) aqueous solution. In the wet impregnation procedure, HZSM-5 powder was impregnated with an aqueous solution of zinc nitrate at $353 \mathrm{~K}$ for $2 \mathrm{~h}$. Dry impregnation was done at ambient temperature. The sample was then dried at $358 \mathrm{~K}$ overnight and calcinated at $773 \mathrm{~K}$ in air atmosphere for $10 \mathrm{~h}$. The zinc content of the resulting catalysts was measured using both wet chemistry and ICP methods.

Bimetallic catalysts were synthesized using dry impregnation of the 0.4 wt\% Zn-loaded HZSM-5 (0.4Zn/HZSM-5) sample with the corresponding metal salts $\left(\mathrm{La}\left(\mathrm{NO}_{3}\right)_{3} \cdot 6 \mathrm{H}_{2} \mathrm{O}, \mathrm{Co}\left(\mathrm{NO}_{3}\right)_{2} \cdot 6 \mathrm{H}_{2} \mathrm{O}, \mathrm{PdCl}_{2}\right.$, and $\mathrm{H}_{2} \mathrm{PtCl}_{6} .6 \mathrm{H}_{2} \mathrm{O}$ ) to achieve 1.0, 2.0, 0.20, and $0.20 \mathrm{wt} \%$ $\mathrm{La}, \mathrm{Co}, \mathrm{Pd}$, and $\mathrm{Pt}$ loadings, respectively. The loading levels of the second metal were chosen according to optimum values for a co-aromatization reaction, as reported in the literature. The catalysts were named according to the amount and symbol of the promoter used and support type.

The calcined sample was crushed and sieved to a 35-70 mesh for a catalytic performance evaluation. 


\subsection{Catalyst characterization}

Nitrogen adsorption-desorption experiments at $77 \mathrm{~K}$ were conducted in an automatic analyzer (Quantachrome NOVA 1000). The surface areas and average pore sizes were obtained using Brunauer-Emmet-Teller (BET) and Barrett-Joyner-Hallender (BJH) methods, respectively. The total pore volumes were derived from the nitrogen-adsorbed volume at relative pressure of $P / P_{0}=0.99$.

The structure of the catalysts was determined by an X-Ray Diffraction (XRD) pattern. Such an analysis was carried out applying the GNR MPD 3000 using Cu $\mathrm{K} \alpha$ radiation in the scanning angle $(2 \theta)$ range of $4-70^{\circ}$ $(\lambda=1.5406 \AA)$.

The morphology and microstructure of the samples were studied using the Scanning Electron Microscopy (SEM) model VEGA TESCAN. Prior to this measurement, the samples were coated with a thin layer of gold.

Temperature-programmed desorption of ammonia $\left(\mathrm{NH}_{3}-\mathrm{TPD}\right.$, using the BELCAT A instrument) was performed in order to determine distribution and strength of acid sites. The sample $(0.09 \mathrm{~g})$ was dried in the helium stream at $773 \mathrm{~K}$ for $1 \mathrm{~h}$ prior to adsorption. Pure $\mathrm{NH}_{3}$ was adsorbed on the catalyst samples until the occurrence of saturation at $373 \mathrm{~K}$. The catalyst was then flushed with helium at $373 \mathrm{~K}$ for $30 \mathrm{~min}$. TPD measurements were conducted within a temperature range of 373 to $1173 \mathrm{~K}$ at a heating rate of $10 \mathrm{~K} / \mathrm{min}$ applying helium as the carrier gas. The desorbed $\mathrm{NH}_{3}$ was measured using a Thermal Conductivity Detector (TCD).

\subsection{Catalytic evaluation}

Catalytic test runs were carried out in a continuous flow, fixed-bed stainless steel reactor (i.e. $8 \mathrm{~mm}$ ) at atmospheric pressure. The catalyst bed was first pretreated with $\mathrm{N}_{2}$ at a reaction temperature for 30 min. In the next step, the feed $\left(\mathrm{CH}_{4}, \mathrm{C}_{3} \mathrm{H}_{8}\right.$, and $\mathrm{N}_{2}$ mixture) was introduced into the reactor after passing through mass flow controllers. $\mathrm{N}_{2}$ was used as an internal standard so that $\mathrm{CH}_{4}$ and $\mathrm{C}_{3} \mathrm{H}_{8}$ conversions could be determined. The feed mixture and products were analyzed using a Varian CP-3800 gas chromatograph with a Flame Ionization Detector (FID) and a GS-GASPRO column to separate hydrocarbons. The Thermal Conductivity Detector (TCD) and MS-5A column were applied to measure $\mathrm{N}_{2}$. The reactor outlet pipeline and gas sampling valves were kept at a tem- perature above $483 \mathrm{~K}$ to avoid product condensation and achieve effective sampling of the total aromatic products.

Methane and propane conversions were calculated according to Eqs. (1) and (2), respectively:

Methane conversion $=$

$$
\begin{aligned}
& {\left[\frac{F^{\text {inlet }} \times X_{\text {methane }}^{\text {inlet }}-F^{\text {outlet }} \times X_{\text {methane }}^{\text {outlet }}}{F^{\text {inlet }} \times X_{\text {methane }}^{\text {inlet }}}\right]} \\
& \times 100=\left[1-\frac{X_{\text {methane }}^{\text {outlet }} \times X_{N_{2}}^{\text {inlet }}}{X_{\text {methane }}^{\text {inlet }} \times X_{N_{2}}^{\text {outlet }}}\right] \times 100,
\end{aligned}
$$

Propane conversion $=$

$$
\begin{aligned}
& {\left[\frac{F^{\text {inlet }} \times X_{\text {propane }}^{\text {inlet }}-F^{\text {outlet }} \times X_{\text {propane }}^{\text {outlet }}}{F^{\text {inlet }} \times X_{\text {propane }}^{\text {inlet }}}\right]} \\
& \times 100=\left[1-\frac{X_{\text {propane }}^{\text {outlet }} \times X_{N_{2}}^{\text {inlet }}}{X_{\text {propane }}^{\text {inlet }} \times X_{N_{2}}^{\text {outlet }}}\right] \times 100,
\end{aligned}
$$

where $F$ and $X$ are the mass flow rate and mass fraction, respectively. The selectivity of the individual products was determined by Eq. (3) as shown in Box I.

\section{Results and discussion}

\subsection{Catalyst characterization}

The XRD pattern of Zn/HZSM-5 containing different amounts of $\mathrm{Zn}$ was measured. The XRD patterns of NaZSM-5 and 4 wt\% Zn-loaded HZSM-5 (4Zn/HZSM$5)$ samples are shown in Figure 1. In all cases, sharp peaks were observed in $2 \theta=8^{\circ}-10^{\circ}$ and $2 \theta=22.5^{\circ}-25^{\circ}$, which are exclusively indexed to the structure of MFI topology. Zn/HZSM-5 samples exhibited no characteristic diffraction peaks of $\mathrm{ZnO}$. However, upon incorporating of $\mathrm{Zn}$, the intensity diffraction peaks of $2 \theta=22.5^{\circ}-25^{\circ}$, compared to the parent zeolite, decreased. This phenomenon might result from a certain absorption coefficient of $\mathrm{Zn}^{2+}$ covering ZSM-5 particles [14]. The XRD patterns for the bimetallic catalysts were also almost identical to those of Zn/HZSM-5, as shown in Figure 1. This could be due to the low loading of metals and their high dispersion in the zeolite matrix [10].

The physical characteristics of all the obtained samples were measured using $\mathrm{N}_{2}$ adsorption/desorption. The results are listed in Table 1.

$$
\text { Products selectivity }=\left[\frac{\text { weight } \% \text { of the product in the hydrocarbon products }}{100-(\text { weight } \% \text { of reactants in the hydrocarbon products })}\right]
$$


Table 1. Surface area, total pore volume, pore diameter, and $\mathrm{NH}_{3}-\mathrm{TPD}$ of the catalysts.

\begin{tabular}{ccccc}
\hline Catalyst & $\begin{array}{c}\text { BET surface } \\
\text { area }\left(\mathbf{m}^{\mathbf{2}} \mathbf{g}\right)\end{array}$ & $\begin{array}{c}\text { Total pore } \\
\text { volume }(\mathbf{m l} / \mathbf{g})\end{array}$ & $\begin{array}{c}\text { Pore diameter } \\
(\AA)\end{array}$ & $\begin{array}{c}\text { Total } \mathbf{N H}_{\mathbf{3}} \\
\text { desorbed by TPD } \\
(\mathbf{m m o l} / \mathbf{g})\end{array}$ \\
\hline HZSM-5 & 325 & $198.17 \mathrm{e}-3$ & 12.21 & 1.178 \\
0.4Zn/HZSM-5 & 316 & $195.42 \mathrm{e}-3$ & 12.37 & 1.182 \\
1La-0.4Zn/HZSM-5 & 311 & $193.13 \mathrm{e}-3$ & 12.52 & 1.169 \\
$0.2 \mathrm{Pt}-0.4 Z n / H Z S M-5$ & 315 & $195.20 \mathrm{e}-3$ & 12.40 & 1.186 \\
2Co-0.4Zn/HZSM-5 & 308 & $191.78 \mathrm{e}-3$ & 12.73 & 1.238 \\
$0.2 \mathrm{Pd}-0.4 Z n / H Z S M-5$ & 314 & $194.57 \mathrm{e}-3$ & 12.46 & 1.219 \\
\hline
\end{tabular}

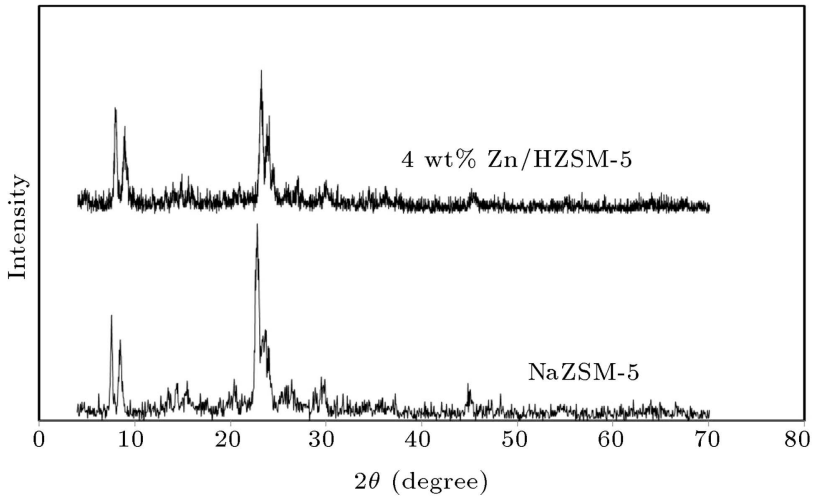

Figure 1. XRD patterns of NaZSM-5 and $4 \mathrm{wt} \%$ Zn/HZSM-5 catalysts.

The surface area and pore volume decreased slightly when the zinc and promoters were loaded onto HZSM5 , which could be attributed to the low uptake of such materials by the samples filling the micropores and mesopores of the parent HZSM-5. The adsorption average pore diameter (calculated from the total pore volume and BET surface area) showed a slight increase when the metals were incorporated with the parent HZSM-5. This could be because the zeolite's micropore volume decreased at a greater rate than its mesopore volume, because the micropore volume was filled with metals, which led to a larger adsorption average pore diameter [14].

$\mathrm{NH}_{3}$-TPD profiles of the samples are shown in Figure 2. The HZSM-5 sample exhibited a typical double-peak characteristic of MFI zeolites at ca. 210 and $430^{\circ} \mathrm{C}$, corresponding to weak and strong acid sites, respectively [10,15-17]. Zinc impregnation caused a considerable decrease in the high-temperature peak (htp), and new adsorption sites were generated. The htp showed a shoulder in the direction of higher temperatures, and the low-temperature peak (ltp) was widened and slightly shifted towards higher temperatures [2].

The high desorption temperature for a portion of the adsorbed ammonia (shoulder in the TPD profile above $500^{\circ} \mathrm{C}$ ) demonstrates that the zinc species are

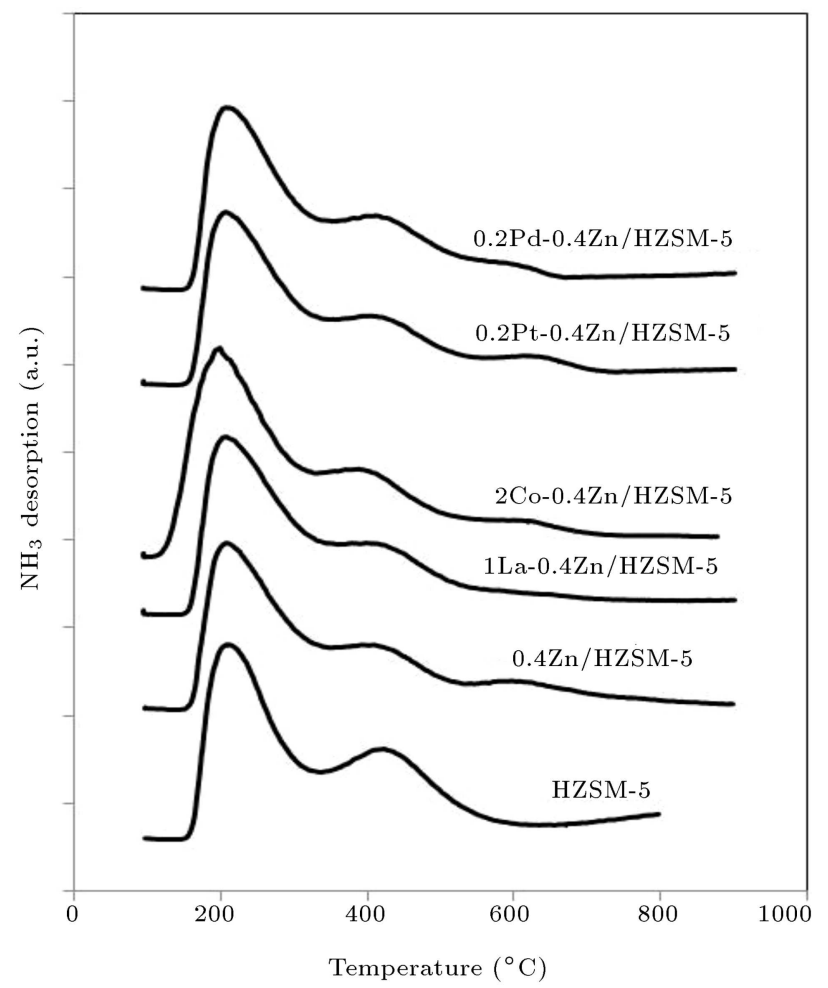

Figure 2. $\mathrm{NH}_{3}-\mathrm{TPD}$ profiles of the catalyst samples.

stronger acidic sites than Lewis acid sites are [2]. Furthermore, Co-Zn/HZSM-5 and Pd-Zn/HZSM-5 samples showed a slight increase in ammonia desorption, compared to HZSM-5. However, La-Zn/HZSM-5 sample had the opposite result.

The Scanning Electron Microscopy (SEM) images of parent ZSM-5 and 0.4Zn/HZSM-5 samples are shown in Figure 3. The crystal sizes are between 150-250 $\mathrm{nm}$. Both the parent ZSM-5 and treated samples exhibited twinned crystals with smooth surfaces. In addition, the cubic particles and agglomeration of particles were clearly observable. It is worth noting that the impregnation process did not change the crystal size distribution of the catalysts; however, the surface of the crystals became a little smoother than HZSM-5. 

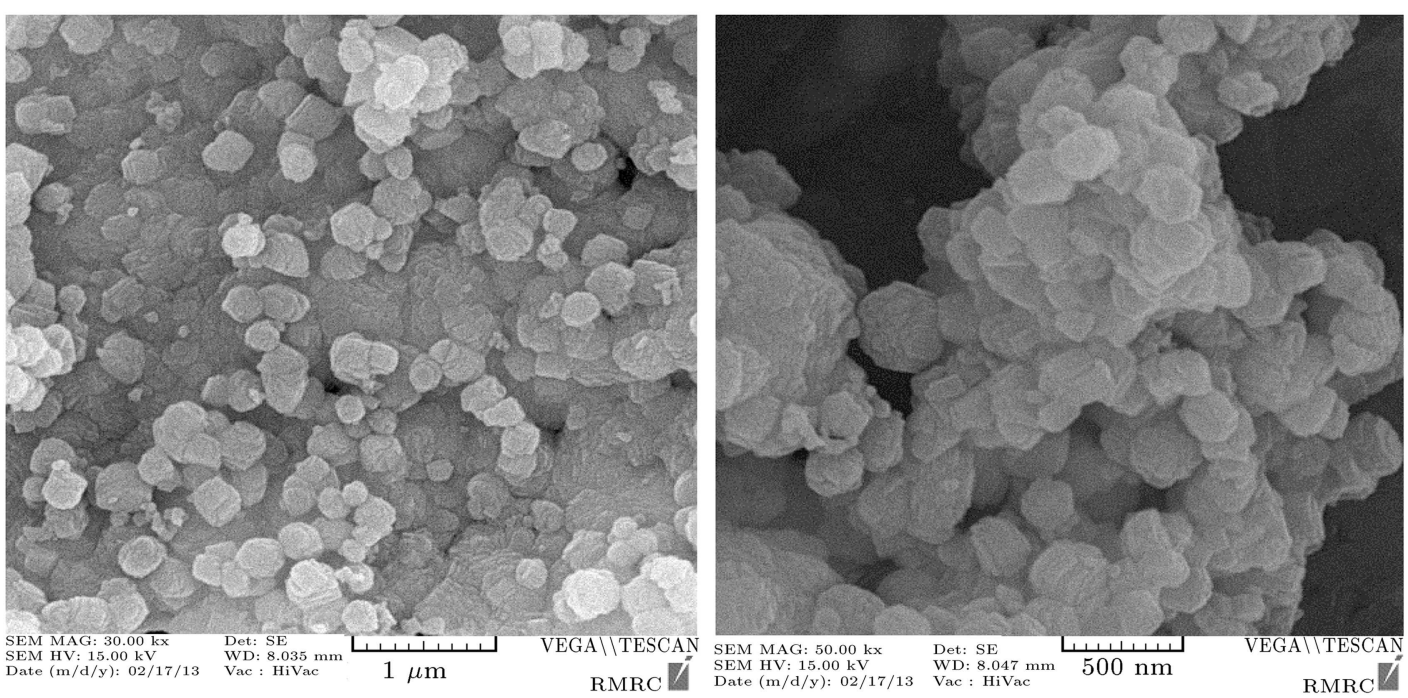

(a)

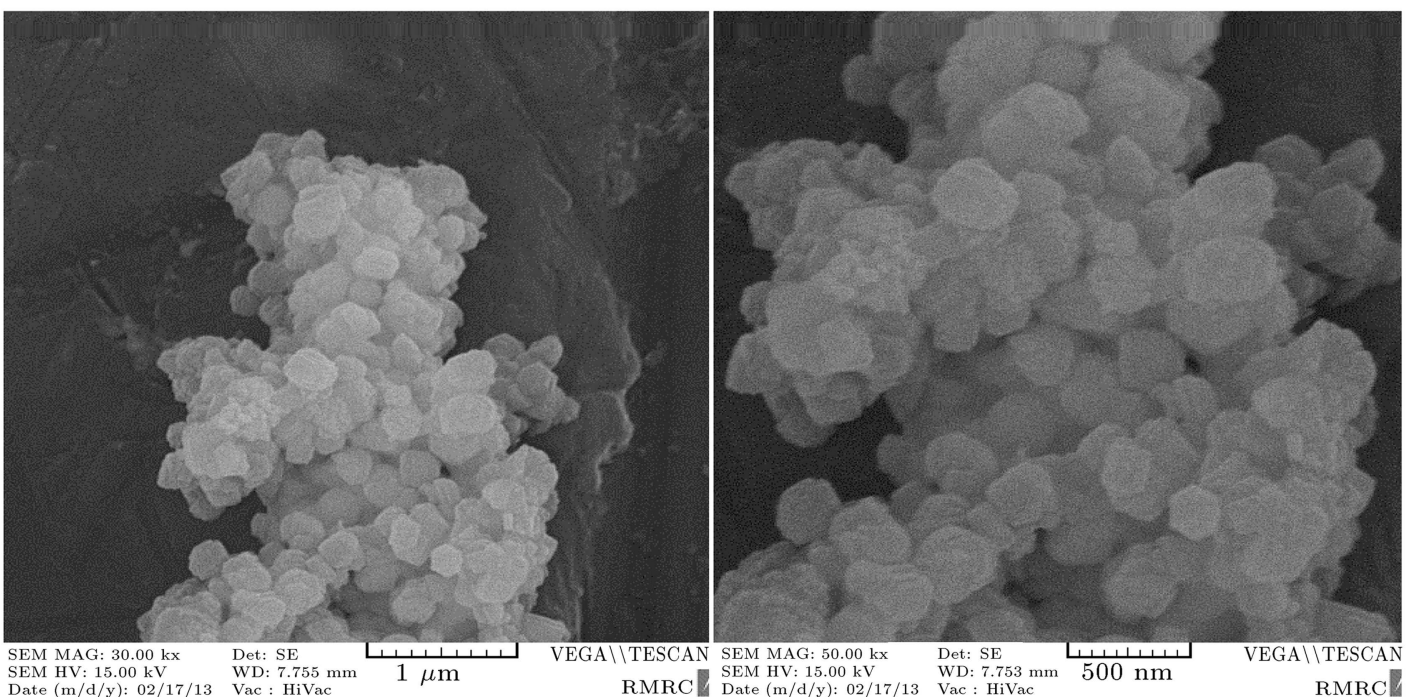

(b)

Figure 3. SEM image of (a) NaZSM-5 and (b) 0.4Zn/ZSM-5.

\subsection{Results of the catalytic tests}

\subsubsection{Zn/HZSM-5 catalysts}

To better consider the effects of each component of feed (methane and propane) in aromatization, it is necessary to evaluate the conversions of pure methane, pure propane, and a mixture of methane and propane as a feed over $0.4 \mathrm{Zn} / \mathrm{HZSM}$. The results are shown in Figure 4. The pure methane conversion was very low. Co-feeding the propane even resulted in a lower conversion of methane, showing that some methane might form from propane (Figure 4(a)). In contrast, the propane conversion was much higher and was virtually unaffected by the addition of methane to the reaction mixture (Figure 4(b)).

The effect of zinc and its contents was studied. Table 2 shows methane and propane conversions together with individual product selectivity over HZSM-
5 and Zn/HZSM-5 prepared by wet impregnation. The addition of zinc did not prompt any considerable change in the conversion of feed components; however, the selectivity to aromatics increased from 45 to 61.6 with the addition of $0.25 \mathrm{wt} \% \mathrm{Zn}$ to HZSM- 5 and passed a maximum at $0.4 \mathrm{wt} \% \mathrm{Zn}$ loading. However, a further increase in zinc content led to a reduction of aromatics' selectivity.

Zinc plays a two-fold role. It introduces dehydrogenation activity to the catalyst and increases the Lewis acid sites' concentration, both of which are beneficial for aromatization. Unlike Br $\phi$ nsted acid sites which promote cracking reactions, Lewis acid sites enhance a desirable dehydroaromatization reaction. There is a general agreement that the major role of the element zinc is to accelerate the combination of surface hydrogen formed via the dehydrogenation and dehydro- 
Table 2. Conversion and selectivity of the key products.

\begin{tabular}{|c|c|c|c|c|c|c|c|c|c|c|c|}
\hline \multirow[t]{2}{*}{ Catalyst } & \multicolumn{2}{|c|}{ Conversion } & \multicolumn{9}{|c|}{ Products selectivity (as C) $\%^{*}$} \\
\hline & $C_{1}$ & $C_{3}$ & $C_{2}$ & $C_{2}=$ & $C_{3}=$ & $\mathbf{B}$ & $\mathbf{T}$ & $\mathbf{X}$ & $C_{9}$ & $\mathbf{N}$ & Total aromatics \\
\hline HZSM-5 & 3 & 68.3 & 13.6 & 22.5 & 15.5 & 16.1 & 20.4 & 6.6 & 1.3 & 0.7 & 45 \\
\hline $0.25 \mathrm{Zn} / \mathrm{HZSM}-5$ & 6 & 61.5 & 8.1 & 17.5 & 9.2 & 23.9 & 26.8 & 8.3 & 1.3 & 1.3 & 61.6 \\
\hline $0.4 \mathrm{Zn} / \mathrm{HZSM}-5$ & 5.4 & 66 & 8.1 & 12.2 & 8.7 & 26.9 & 31.4 & 8.6 & 1.7 & 2.3 & 71.8 \\
\hline $0.6 \mathrm{Zn} / \mathrm{HZSM}-5$ & 5.6 & 62.6 & 7 & 14.2 & 8.8 & 26 & 30.6 & 8.6 & 1.9 & 1.9 & 69.4 \\
\hline
\end{tabular}

*B: benzene, T: toluene, X: xylenes, $\mathrm{N}$ : naphthalene.

Reaction condition: $\mathrm{CH}_{4} / \mathrm{C}_{3} \mathrm{H}_{8} / \mathrm{N}_{2}=6 / 1 / 1.3$. $\mathrm{T}=823 \mathrm{~K}, \mathrm{P}=1 \mathrm{~atm}, \mathrm{GHSV}=1500 \mathrm{ml} \cdot \mathrm{g}_{\text {cat }}^{-1} \cdot \mathrm{h}^{-1}$, T.O.S $=15 \mathrm{~min}$.

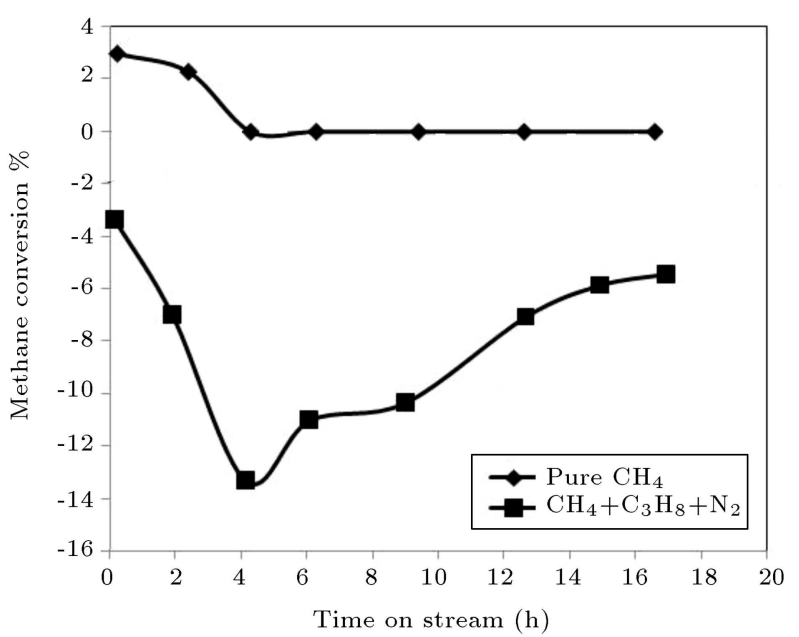

(a)

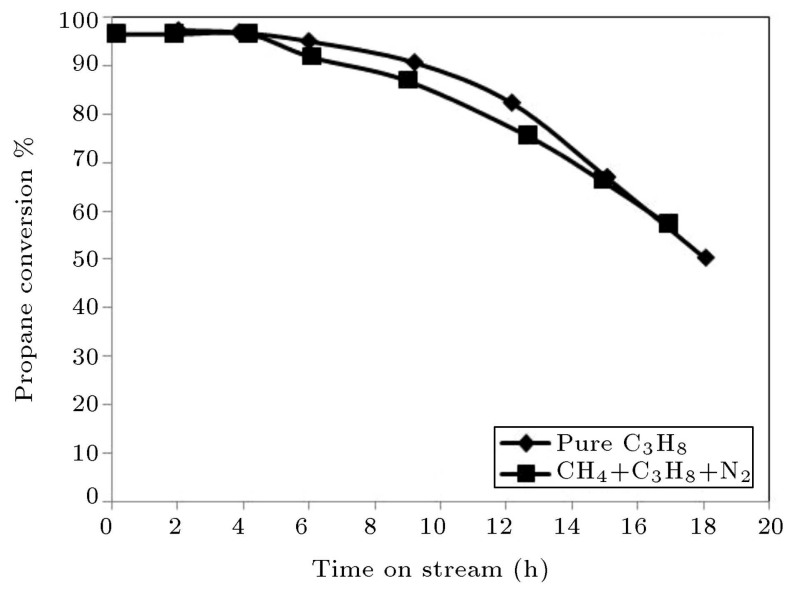

(b)

Figure 4. Methane conversion (a) and propane conversion (b) over $0.4 \mathrm{Zn} / \mathrm{HZSM}-5$ catalyst as functions of time on stream. Feed: pure $\mathrm{CH}_{4}$, pure $\mathrm{C}_{3} \mathrm{H}_{8}$, and $\mathrm{CH}_{4} / \mathrm{C}_{3} \mathrm{H}_{8} / \mathrm{N}_{2}=$ $6 / 1 / 1.3 . T=873 \mathrm{~K}, \mathrm{GHSV}=1500 \mathrm{ml} \cdot \mathrm{g}_{\mathrm{cat}}^{-1} \cdot \mathrm{h}^{-1}$.

cyclization process involved as key steps in converting alkanes to aromatics via alkenic intermediates. In the absence of surface hydrogen removal (in the form of dihydrogen), there is a marked tendency for hydrogen participation in hydrogen transfer processes. The direct transfer of hydrogen in protonic form from alkenic intermediates during the dehydrocyclization step to other alkenic intermediates results in the formation of alkanes as byproducts, thereby limiting the Benzene, Toluene and Xylene (BTX) selectivity. This is the case for the HZSM-5 catalyst, and the subsequent hydrogen transfer places a severe upper limit on the potential BTX selectivity [18].

Compared to wet impregnation with a maximum zinc loading of $0.6 \mathrm{wt} \%$, dry impregnation provides higher zinc loading. It was found that the concentration profile of the metallic zinc on the support could be adjusted by the concentration of the zinc salt in the solution or by controlling the temperature of impregnation [19]. During dry impregnation, the exact amount of liquid zinc solution was used to fill the pore volume of the support, whereas, in wet impregnation, the amount of liquid was controlled by the solubility of the metal precursor. Hence, in the latter method, due to the mass diffusion resistance in solution penetration into the support, the metallic zinc loading is expected to be less than that in dry impregnation. Hence, for higher zinc loading, dry impregnation methods were used. The impregnation method for zinc had important effects on the catalyst performance.

Figure 5(a) and (b) show the results of methane and propane conversions over xZn/HZSM-5 ( $x=$ 1,2 , and $3 \%$ ) prepared by dry impregnation. At the beginning of the runs, methane conversions were positive even over the unpromoted HZSM-5 sample, exhibiting an "initial period of activity" with the highest conversion. However, methane conversions were not stable and rapidly approached almost zero or even negative values, illustrating that methane could, in fact, be produced rather than consumed on a net basis.

The addition of 0.4 wt\% zinc using the wet impregnation method did not change the propane conversion; however, it was markedly enhanced by the addition of $1 \mathrm{wt} \%$ or more zinc using the dry impregnation method. This showed that the method of zinc loading is very important.

The selectivity of aromatics rises markedly with the addition of Zn to HZSM-5 by either impregnation method (Table 2 and Figure 5(c)). However, the propane conversion and aromatics' selectivity were 
relatively stable only on $0.4 \mathrm{Zn} / \mathrm{HZSM}-5$ with time on stream, whereas both decreased with time over Zn/HZSM-5 catalysts prepared using dry impregnation. In the wet impregnation method, zinc deposits

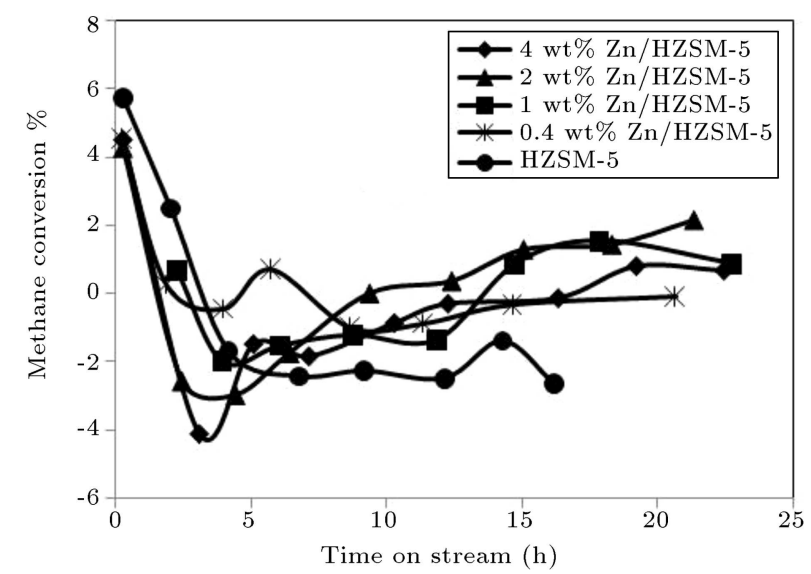

(a)

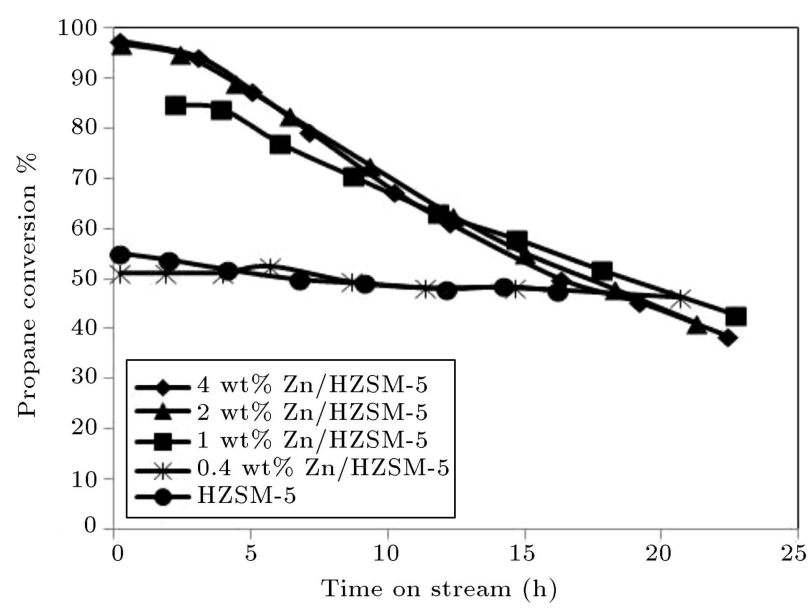

(b)

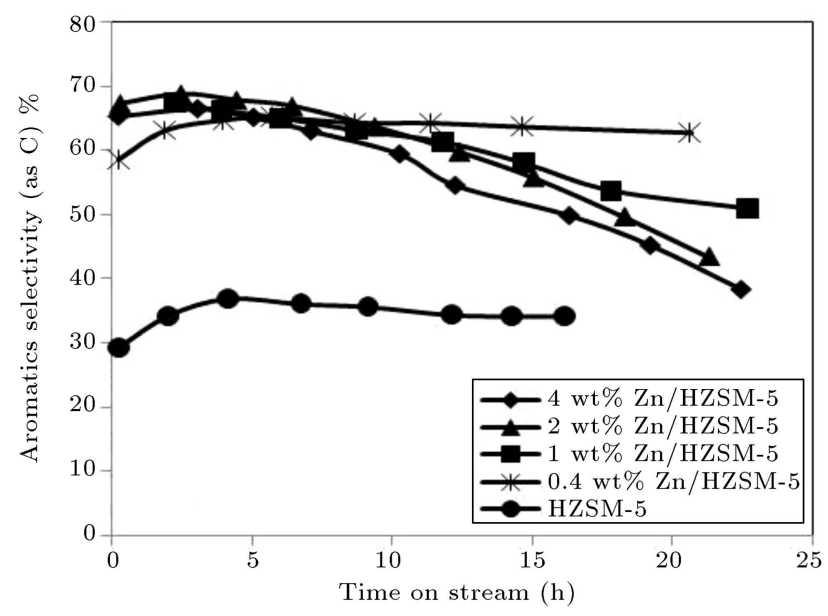

(c)

Figure 5. Methane conversion (a), propane conversion (b), and aromatics $\left(C_{6}-C_{10}\right)$ selectivity (c) as functions of time on stream. Feed: $\mathrm{CH}_{4} / \mathrm{C}_{3} \mathrm{H}_{8} / \mathrm{N}_{2}=6 / 1 / 1.3 . T=823$ $\mathrm{K}, P=1 \mathrm{~atm}$, and $\mathrm{GHSV}=3000 \mathrm{ml} \cdot \mathrm{g}_{\text {cat }}^{-1} \cdot \mathrm{h}^{-1}$. by ion exchange with $\mathrm{H}^{+}$sites over a zeolite surface resulted in highly dispersed $\mathrm{Zn}$. In the dry impregnation method, in contrast, due to the low interaction of $\mathrm{Zn}^{2+}$ ions with zeolite support and higher metal loadings, both the dispersion and distribution of $\mathrm{Zn}$ species should be rather poor, causing some pore blockage. Consequently, coke could more rapidly block zeolite pores and cause a higher deactivation rate.

Due to the above results, $0.4 \mathrm{Zn} / \mathrm{HZSM}-5$ was selected for further study.

\subsubsection{Co-promoted $0.4 Z n / H Z S M-5$ catalysts}

As mentioned in the introduction section, some metals can improve the catalyst's performance of Zn/HZSM-5 in light paraffin aromatization. For further study, some of the best metals were chosen and added to Zn/HZSM5. Figure 6 shows the trends of methane and propane conversions over the co-promoted $0.4 \mathrm{Zn} / \mathrm{HZSM}-5$ catalysts. Methane conversion occurred in the first hours

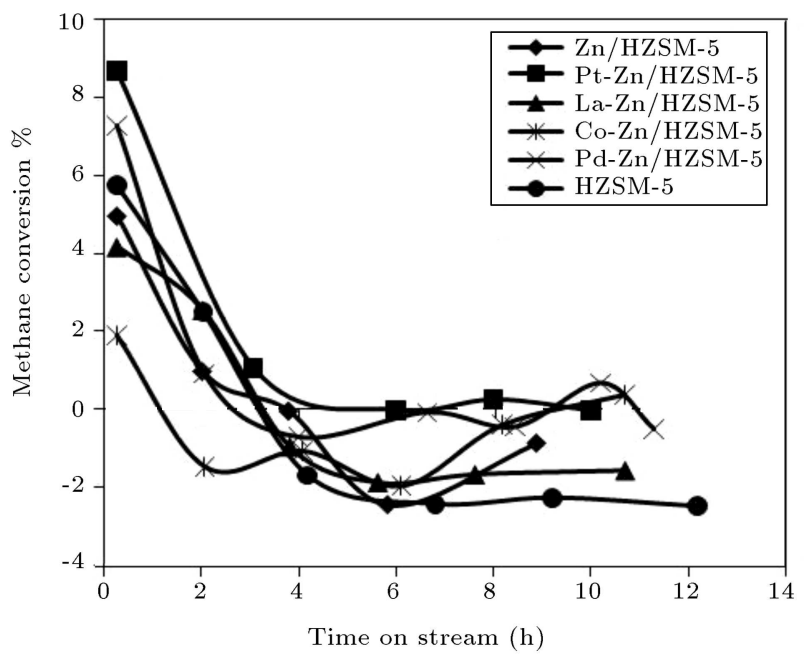

(a)

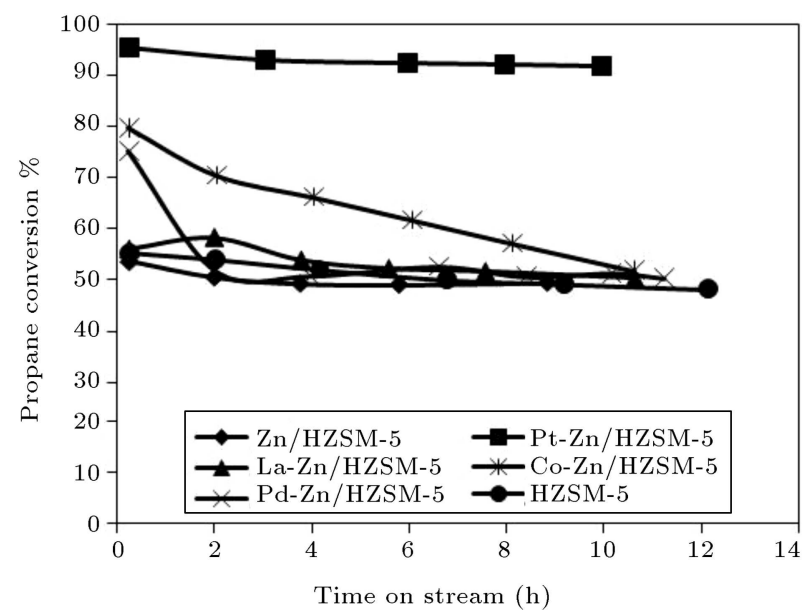

(b)

Figure 6. Methane conversion (a) and propane conversion (b) as functions of time on stream. Feed: $\mathrm{CH}_{4} / \mathrm{C}_{3} \mathrm{H}_{8} / \mathrm{N}_{2}=$ $6 / 1 / 1.3 . T=823 \mathrm{~K}, \mathrm{GHSV}=3000 \mathrm{ml} \cdot \mathrm{g}_{\mathrm{cat}}^{-1} \cdot \mathrm{h}^{-1}$. 
for all the co-promoted $0.4 \mathrm{Zn} / \mathrm{HZSM}-5$ and, then, decreased to zero; furthermore, even methane was produced rather than its consumption. Surprisingly, a similar rapid initial drop in conversion was not observed for propane, indicating that what occurred in the case of the methane could not be related to catalyst deactivation.

The initial activity for methane conversion was the highest (about 10\%) over the Pt-Zn/HZSM-5 catalyst. It is important to note that, in the presence of catalysts containing group VIII metals as promoters (Pt-Zn/HZSM-5, Pd-Zn/HZSM-5 and Co-Zn/HZSM$5)$, no more methane was produced during the reaction. In other words, after about four hours on stream, the methane conversion approached zero.

As may be observed from Figure 6(b), impregnating HZSM-5 with zinc had no substantial effect on propane conversion. However, by incorporating platinum with Zn/HZSM-5 catalysts, propane conversion increased significantly. Platinum exhibits a high activity for dehydrogenation of light alkanes and is likewise an active propane hydrogenolysis catalyst. The addition of platinum enhances the overall catalytic activity by increasing the rate of propane dehydrogenation. However, the positive action of $\mathrm{Pt}$ is accompanied by a hydrogenolysis reaction, which impacts the aromatic yield. The hydrogenolysis of propane to methane occurs mainly on $\mathrm{Pt}$ sites with low coordination numbers, preferentially deactivating during the reaction [20].

In addition, adding palladium and cobalt to Zn/HZSM-5 promoted propane conversion. However, such catalysts deactivated rapidly with time on stream. The total acidity of these catalysts is higher than that of HZSM-5 (Table 1). Hence, the coke formation rate of these catalysts should be greater than that of the rest of the aromatization catalysts.

The addition of 0.4 wt\% Zn to HZSM-5 (Figure $7(\mathrm{a})$ ) markedly improved the selectivity to aromatics. The effect on the overall aromatic selectivity of adding the second species to modified Zn catalysts was, however, not so pronounced. The highest aromatic yield was observed in the case of HZSM-5 catalysts which were promoted with both zinc and platinum.
Table 3 shows the products' selectivity after 15 min on stream, which may approximate the performance of the fresh catalysts. Tables 2 and 3 illustrate that the aromatic cut consisted mainly of benzene and its methylated homologues. The aromatic selectivity over HZSM-5 was meager. The addition

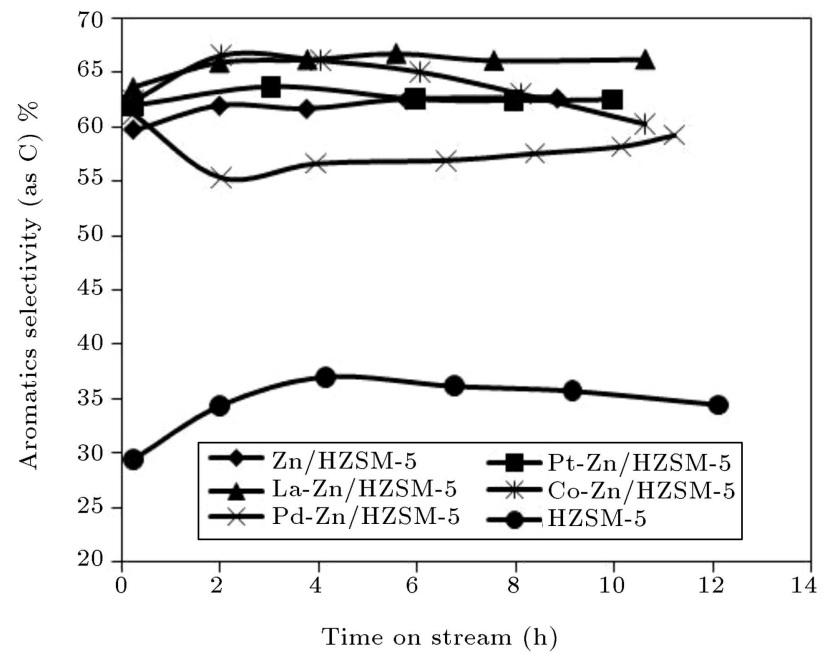

(a)

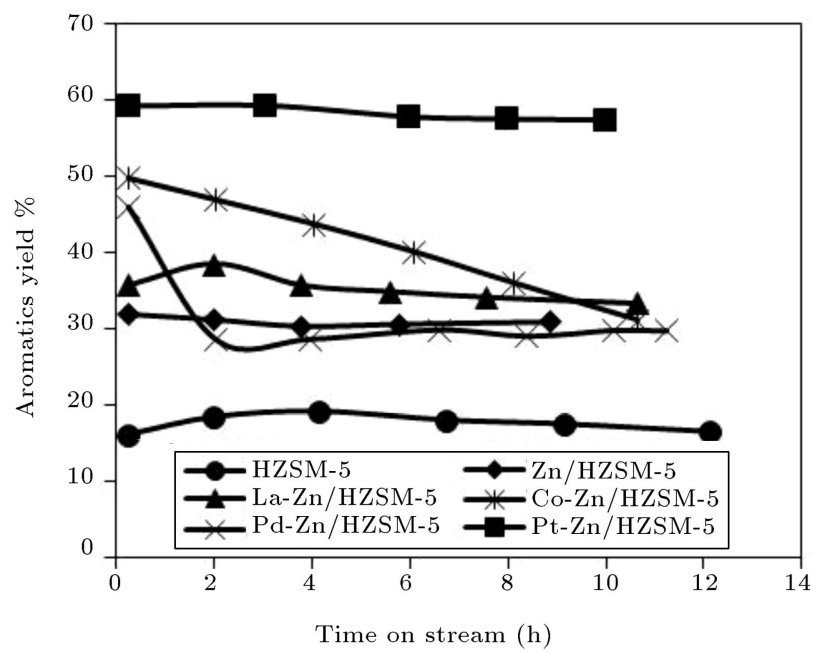

(b)

Figure 7. Aromatics $\left(C_{6}-C_{10}\right)$ selectivity (a) and yield (b) as functions of time on stream. Feed: $\mathrm{CH}_{4} / \mathrm{C}_{3} \mathrm{H}_{8} / \mathrm{N}_{2}=$ $6 / 1 / 1.3 . T=823 \mathrm{~K}, \mathrm{GHSV}=3000 \mathrm{ml} \cdot \mathrm{g}_{\mathrm{cat}}^{-1} \cdot \mathrm{h}^{-1}$.

Table 3. selectivity of the key products.

\begin{tabular}{ccccccccc}
\hline \multirow{2}{*}{ Catalyst } & \multicolumn{7}{c}{ Selectivity to products (as C) $\boldsymbol{\%}^{*}$} \\
\cline { 2 - 9 } & $\boldsymbol{C}_{\mathbf{2}}$ & $\boldsymbol{C}_{\mathbf{2}}=$ & $\boldsymbol{C}_{\mathbf{3}}=$ & $\mathbf{B}$ & $\mathbf{T}$ & $\mathbf{X}$ & $\boldsymbol{C}_{\mathbf{9}}$ & $\mathbf{N}$ \\
\hline HZSM-5 & 7.58 & 37.8 & 20.4 & 7.88 & 9.29 & 3.3 & 8.82 & 0 \\
$0.4 Z n / H Z S M-5$ & 4.82 & 21.2 & 12 & 23.2 & 26.8 & 8.2 & 0.76 & 0.8 \\
1La-0.4Zn/HZSM-5 & 9.37 & 13.9 & 10.8 & 23.6 & 28.3 & 9.2 & 1.3 & 1.3 \\
$0.2 \mathrm{Pt}-0.4 Z n / H Z S M-5$ & 33.5 & 1.39 & 2.53 & 19.6 & 31.1 & 8.3 & 1 & 2 \\
2Co-0.4Zn/HZSM-5 & 24.5 & 3.9 & 8.21 & 26.1 & 25.9 & 3.6 & 0.96 & 5.8 \\
$0.2 \mathrm{Pd}-0.4 Z n / H Z S M-5$ & 25.8 & 3.96 & 7.62 & 19.5 & 30 & 8.5 & 1.84 & 1.4 \\
\hline${ }^{* B}$ benzene, T: toluene, $\mathrm{X:} \mathrm{xylenes,} \mathrm{N}:$ naphthalene. \\
Reaction condition: $\mathrm{CH}_{4} / \mathrm{C}_{3} \mathrm{H}_{8} / \mathrm{N}_{2}=6 / 1 / 1.3, T=823 \mathrm{~K}, \mathrm{GHSV}=3000 \mathrm{ml.g}_{\text {cat }}^{-1} \cdot \mathrm{h}^{-1}, \mathrm{TOS}=15 \mathrm{~min}$.
\end{tabular}


of Zn element strongly enhanced aromatic selectivity. The Zn/HZSM-5 catalysts contain medium acidity that minimizes the occurrences of cracking side reactions. Zinc cations, as Lewis acid sites, promote alkane dehydrogenation to alkenes, which are the precursors of aromatics.

The addition of La improved aromatic selectivity at the expense of cracking products as indicated by the decreased $C_{2}=$ selectivity. La transforms a part of strong $\operatorname{Br} \phi$ nsted acid sites to strong Lewis acid sites by dispersing or exchanging with $\mathrm{H}^{+}$of the zeolite, thereby decreasing the cracking activity. A rare earth-exchanged zeolite increases the hydrogen transfer reaction. The rare-earth elements, being trivalent, form bridges between two or three acid sites in the catalyst framework. Because hydrogen transfer needs adjacent sites, bridging these sites with rareearth elements promotes hydrogen transfer reactions, forming aromatics (and paraffins) from olefins [21].

The selectivity of the main byproducts is depicted in Figure 8, which is a function of time-onstream theory over $2 \mathrm{Co}-0.4 \mathrm{Zn} / \mathrm{HZSM}-5$ and $0.2 \mathrm{Pd}-$ 0.4Zn/HZSM-5 catalysts, which exhibited the lowest stabilities. Similar trends were observed for selectivity to ethylene and propylene. As it can be seen from this figure, selectivity to ethane decreased with time on stream function, whereas selectivity to propylene and ethylene enhanced. The above results imply that the zeolite acid sites deactivated faster than those of dehydrogenation, and that the main reason for the catalyst deactivation is coke deposition on zeolite acid sites. The deactivation of zeolite catalysts may occur by various mechanisms, including site poisoning and coke formation. Carbonaceous deposits limit reactants' access to active sites due to site coverage, or partial or complete blockage of pores [22,23]. In the case of bi-functional catalysts, another possible source of deactivation is the sintering of supported metal species [24,25].

Group VIII metals impose both propane dehydrogenation and hydrogenolysis activity on the catalyst. Incorporating these metals reduces propane cracking activity while, remarkably, also promotes hydrogenolysis, as indicated by the sharp increase in ethane selectivity. The hydrogen required for hydrogenolysis is produced as a byproduct of the dehydroaromatization reaction. The decrease in propylene selectivity with the promoted catalysts, compared with that of unmodified zeolites, can be explained by utilization of such an intermediate product by the improved catalysts.

\section{Conclusions}

The analysis of the conversion/selectivity results of the methane/propane feed mixture over the HZSM-5 catalyst promoted by zinc and with the second metal

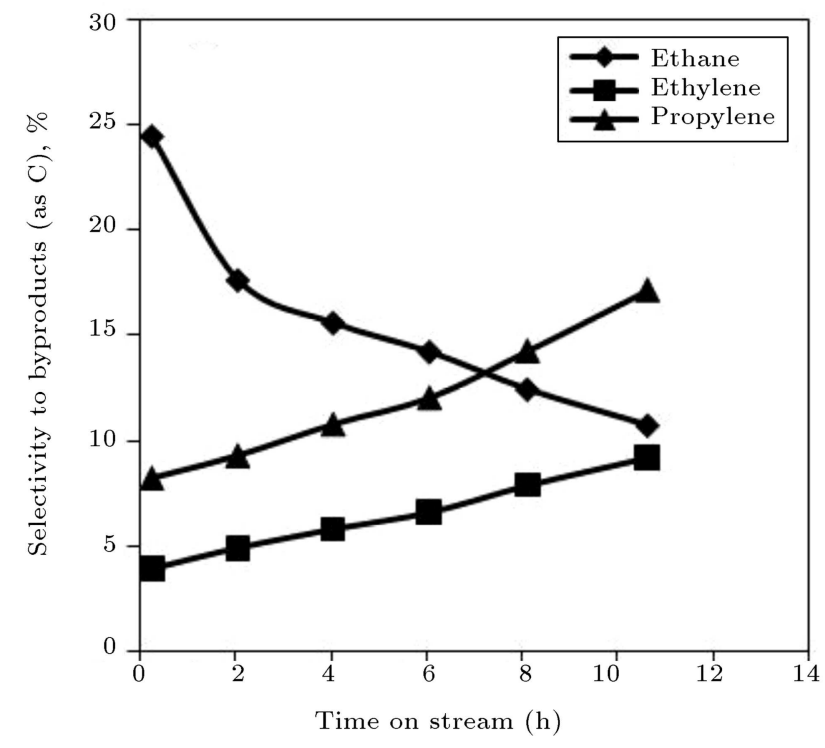

(a)

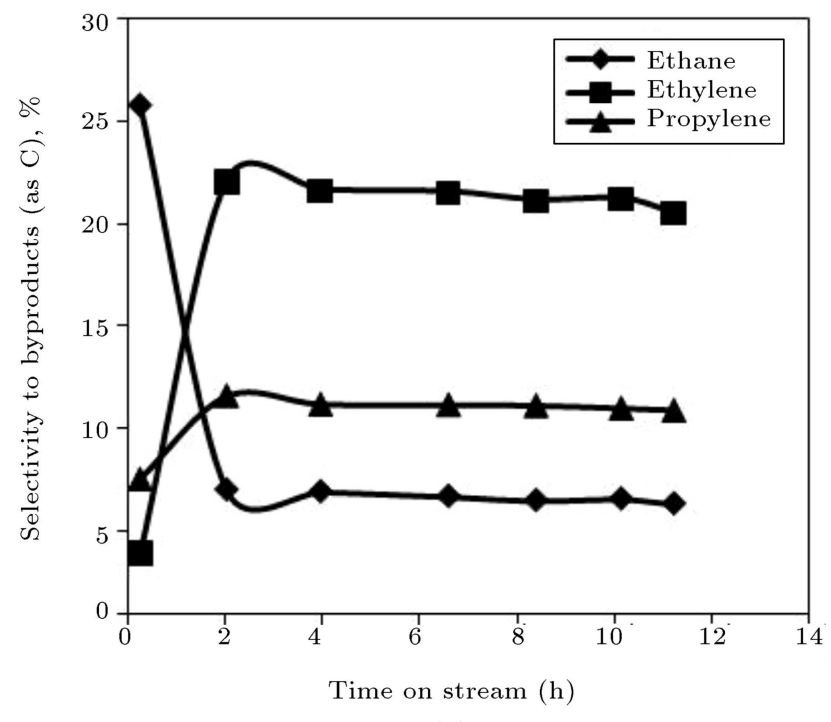

(b)

Figure 8. Byproducts selectivity on (a) $2 \mathrm{Co}-0.4 \mathrm{Zn} / \mathrm{HZSM}-5$ and (b) $0.2 \mathrm{Pd}-0.4 \mathrm{Zn} / \mathrm{HZSM}-5$ as functions of time on stream. Feed: $\mathrm{CH}_{4} / \mathrm{C}_{3} \mathrm{H}_{8} / \mathrm{N}_{2}=$ $6 / 1 / 1.3 . T=823 \mathrm{~K}, \mathrm{GHSV}=3000 \mathrm{ml} \cdot \mathrm{g}_{\mathrm{cat}}^{-1} \cdot \mathrm{h}^{-1}$.

showed that the aromatic yield can drastically increase by promotion. However, the following observations suggest that the improved aromatic yield could not be the result of methane involvement:

- Adding propane to pure methane does not enhance methane conversion and may even decrease it due to the formation of methane as a byproduct of propane reactions;

- The promoters enhance mostly propane conversion with little effect on methane conversion;

- The seemingly similar methane conversion trends over different catalysts characterized by short initial activity followed by a rapid drop of conversion imply 
that some noncatalytic transient processes may be involved in the observed behavior;

- The time-on-stream behaviors of methane and propane conversions are substantially different rendering the involvement of common active site or significant stoichiometric reaction between methane and propane unlikely.

\section{Acknowledgements}

The authors gratefully acknowledge the financial support received in the form of a research grant from National Petrochemical Co., Research and Technology Co. (NPC-RT), Iran.

\section{References}

1. Aboul-Gheit, A.K., Awadallah, A.E., El-Kossy, S.M., and Mahmoud, AL.H. "Effect of $\mathrm{Pd}$ or $\mathrm{Ir}$ on the catalytic performance of Mo/H-ZSM-5 during the nonoxidative conversion of natural gas to petrochemicals", J. Nat. Gas Chem., 17, pp. 337-343 (2008).

2. Berndt, H., Lietz, G., Lücke, B., and Völter, J. "Zinc promoted H-ZSM-5 catalysts for conversion of propane to aromatics I. Acidity and activity", Appl. Catal. A: Gen., 146, pp. 351-363 (1996).

3. Bhan, A., Hsu, S.H., Blau, G., Caruthers, J.M., Venkatasubramanian, V., and Delgass, W.N. "Microkinetic modeling of propane aromatization over HZSM5", J. Catal., 235, pp. 35-51 (2005).

4. Moghimpour Bijani, P., Sohrabi, M., and Sahebdelfar, S. "Thermodynamic analysis of nonoxidative dehydroaromatization of methane", Chem. Eng. Technol., 35, pp. 1825-1832 (2012).

5. Lukyanov, D.B. and Vazhnova, T. "Selective and stable benzene alkylation with methane into toluene over PtH-MFI bifunctional catalyst", J.Mol. Catal. A: Chem., 305, pp. 95-99 (2009).

6. Choudhary,V.R., Kinage, A.K., and Choudhary, T.V. "Low-temperature nonoxidative activation of methane over H-galloaluminosilicate (MFI) zeolite", Science, 275, pp. 1286-1288 (1997).

7. Chu, W. and Qiu, F. "Remarkable promotion of benzene formation in methane aromatization with ethane addition", Top. Catal., 22, pp. 131-134 (2003).

8. Echevsky, G., Kodenev, E., Kikhtyanin, O., and Parmon, V. "Direct insertion of methane into $\mathrm{C}_{3-}$ $\mathrm{C}_{4}$ paraffins over zeolite catalysts: a start to the development of new one-step catalytic processes for the gas-to-liquid transformation", Appl. Catal. A: Gen., 258, pp. 159-171 (2004).

9. Guo, J., Lou, H., and Zheng, X. "Energy-Efficient coaromatization of methane and propane", J. Nat. Gas Chem., 18, pp. 260-272 (2009).

10. Asaftei, I.V., Bilba, N., Birsa, L.M., and Iofcea, Gh. "Aromatization of industrial feedstock mainly withbutanes and butenes over HZSM- 5 and Zn/HZSM5catalysts", Acta. Chem. IASI, 17, pp. 5-34 (2009).

11. Naccache, C.M., Mériaudeau, P., Sapaly, G., Van Tiep, L., and Ben Taârit, Y. "Assessment of the lowtemperature nonoxidative activation of methane over H-galloaluminosilicate (MFI) zeolite: A C-13 labelling investigation", J.Catal., 205, pp. 217-220 (2002).

12. Bradford, M.C.J, Te, M., Konduru, M., and Fuentes, D.X. " $\mathrm{CH}_{4}-\mathrm{C}_{2} \mathrm{H}_{6}-\mathrm{CO}_{2}$ conversion to aromatics over Mo/SiO $/ \mathrm{Si}_{2} / \mathrm{H}-\mathrm{ZSM}-5 "$, Appl. Catal. A: Gen., 266, pp. 55-66 (2004).

13. Luzgin, M.V., Rogov, V.A., Arzumanov, S.S., Toktarev, A.V., Stepanov, A.G., and Parmon, V.N. "Methane aromatization on Zn-modified zeolite in the presence of a co-reactant higher alkane: How does it occur?", Catal. Today, 144, pp. 265-272 (2009).

14. Zhao, X., Wei, L., Cheng, S., Huang, Y., Yu, Y., and Julson, J. "Catalytic cracking of camelina oil for hydrocarbon biofuel over ZSM-5-Zn catalyst", Fuel Process Technol., 139, pp. 117-126 (2015).

15. Guo, J., Lou, H., Zhao, H., Zheng, L., and Zheng, X. "Dehydrogenation and aromatization of propane over rhenium-modified HZSM-5 catalyst", J. Mol. Catal. A : Chem., 239, pp. 222-227 (2005).

16. Wang, D., Kan, Q., Xu, N., Wu, P., and Wu, T. "Study on methane aromatization over $\mathrm{MoO}_{3} / \mathrm{HMCM}-49$ catalyst", Catal. Today, 93, pp. 75-80 (2004).

17. Xu, Y., Wang, J., Suzuki, Y., and Zhang, Z.G. "Effect of transition metal additives on the catalytic stability of Mo/HZSM-5 in the methane dehydroaromatization under periodic $\mathrm{CH}_{4}-\mathrm{H}_{2}$ switch operation at 1073K", Appl. Catal. A: Gen., 409-410, pp. 181-193 (2011).

18. Lubango, L.M. and Scurrell, M.S. "Light alkanes aromatization to BTX over Zn-ZSM-5 catalysts: Enhancements in BTX selectivity by means of a second transition metal ion", Appl. Catal. A: Gen., 235(1), pp. 265-272 (2002).

19. Kulkarni, S.S., Mauze, G.R., and Schwarz, J.A. "Concentration profiles and the design of metal-supported catalysts", J. Catal., 69(2), pp. 445-453 (1981).

20. Maggiore, R., Scire, S., Galvango, S., Crisafulli, C., and Toscano, T. "Hydrogenolysis reactions during propane aromatization over Pt/ZSM-5", React. Kinet. Catal. Lett., 46(2), pp. 255-261 (1992).

21. Sadegbeigi, R., Fluid Catalytic Cracking Handbook: An Expert Guide to the Practical Operation, Design, and Optimization of FCC Units, 3th Ed. ButterworthHeinemann, Netherlands (2012).

22. Caeiro, G., Carvalho, R., Wang, X., Lemos, M., Lemos, F., Guisnet, M., and Ramôa Ribeiro, F. "Activation of $\mathrm{C} 2-\mathrm{C} 4$ alkanes over acid and bifunctional zeolite catalysts", J. Mol. Catal. A: Chem., 255, pp. 131-158 (2006).

23. Dong, X., Song, Y., and Lin, W. "A new way to enhance the coke-resistance of Mo/HZSM-5 catalyst for methane dehydroaromatization", Catal. Commun., 8, pp. 539-542 (2007). 
24. Tessonnier, J.P., Louis, B., Rigolet, S., Ledoux, M.J., and Pham-Huu, C. "Methane dehydro-aromatization on Mo/ZSM-5: about the hidden role of $\mathrm{Br} \phi$ nsted acid sites", Appl. Catal. A: Gen., 336, pp. 79-88 (2008).

25. Zheng, L., Xuan, D., Guo, J., Lou, H., and Zheng, X. "Non-oxidative aromatization of $\mathrm{CH}_{4}-\mathrm{C}_{3} \mathrm{H}_{8}$ over Lapromoted Zn/HZSM-5 catalysts", J. Nat. Gas. Chem., 15, pp. 52-57 (2006).

\section{Biographies}

Parisa Moghimpour Bijani obtained her $\mathrm{PhD}$ in Chemical Engineering under supervision of Prof. Morteza Sohrabi from Amirkabir University of Technology in 2013. She is currently working as a researcher in the Catalysis Research Group in Petrochemical Research and Technology Company. Her research interests include paraffin dehydrogenation, light paraffin aromatization, and methanol dehydration. She published more than 30 journal and conference papers.

Morteza Sohrabi received his $\mathrm{PhD}$ from Bradford University in 1968. He worked in Amirkabir University of Technology as an Assistant Professor from 1973 to 1977; Associate Professor from 1977 to 1984; a Professor of Chemical Engineering since 1984; the Chairman of department from 1975 to 1977; the Dean of Faculty of Engineering and Teacher Training from 1977 to 1980, and the Head of Faculty of Chemical
Engineering since 1999. His research interests included catalysis and reaction engineering. He published more than 120 scientific papers in international journals. Unfortunately, he passed away in 2015.

Saeed Sahebdelfar earned his PhD degree in Chemical Engineering from Sharif University of Technology. He is currently the Head of Catalysis Research Group in Petrochemical Research and Technology Company. His research interests are in the field of natural gas conversions and environmental technologies. His main research activities are focused on catalytic oxidative coupling of methane, paraffin dehydrogenation, and carbon dioxide utilization. He published more than 70 scientific papers in international journals.

Abedeh Gholidoust ( $\mathrm{PhD}$ ) received her BSc in Petrochemical Engineering (2007) and MSc in Chemical Engineering (2009) from the Amirkabir University of Technology in Tehran. Since 2009, she has been with the National Petroleum, Polymer and Catalysis institute of Iran as a Research Engineer (2009-2010), and as a Research Assistant with ENSTA at Ecole Polytechnique de Paris (2010-2011). In 2017, she received her $\mathrm{PhD}$ in Environmental Engineering from the University of Alberta. Her research interests include material sustainable development to improve indoor and outdoor air quality. She has co-authored more than 10 journal and conference papers. 